\title{
Natural disasters and firm resilience in Italian industrial districts
}

\author{
Giulio Cainelli \\ Department of Economics and Management, University of Padova, \\ via del Santo 33, 35122 Padova, Italy, email: giulio.cainelli@ unipd.it
}

Andrea Fracasso

Department of Economics and Management and School of International Studies, University of Trento, via Inama 5, 38122 Trento, Italy, email: andrea.fracasso@unitn.it

\section{Giuseppe Vittucci Marzetti}

Department of Sociology and Social Research, University of Milano-Bicocca, Bicocca degli Arcimboldi 8, 20126 Milan, Italy, email: giuseppe.vittucci@unimib.it

\begin{abstract}
We carry out a firm-level empirical analysis to evaluate the economic impact of the sequence of earthquakes occurred in 2012 in the Italian region of Emilia-Romagna, and to address the question of whether the localization of a firm within an industrial district mitigated or exacerbated this impact. We estimate the effect of the earthquake on firms' performance via two alternative methods: Difference-In-Differences and Propensity Score Matching in levels and first-differences. Our findings suggest that the earthquake reduced turnover, production, value added, and return on sales of the surviving firms, at least in the short-term. In addition, the debt over sales ratio grew significantly more in the firms located in the areas affected by the earthquake. The empirical evidence also suggests that the negative impact of the earthquake was slightly higher for the firms located in industrial districts, thereby suggesting that, at least in the short-term, the usually positive cumulative processes associated with localization within an agglomerated area could have reversed and magnified the negative impact of a disruptive exogenous supply shock.
\end{abstract}

Keywords: Agglomeration economies, Natural disaster, Resilience, Industrial districts. 


\section{Introduction}

The impact of natural disasters on economic growth has recently become the object of intense research. As the occurrence of natural events is most often unpredictable, these phenomena can be treated as exogenous shocks and serve as natural experiments to test various hypotheses.

Because of limited data availability, most analyses have been cross-country and based on macroeconomic data. ${ }^{1}$ For those interested in either detecting specific channels of transmission of large supply shocks or assessing how local conditions affect the transmission of shocks, this approach is highly unpalatable. ${ }^{2}$ As pointed out by Barone and Mocetti (2014), the investigation of a large firmlevel dataset offers several advantages over the cross-country analysis and, in particular, it allows detecting how local conditions interact with the shocks, either amplifying or mitigating their effects.

In this paper, we develop a firm-level analysis to identify one specific channel of transmission of a localized natural disaster. In a nutshell, we try to assess whether the location of a firm within an industrial district mitigates or exacerbates the impact of a disaster on the firm's activity and performance. While a consensus has been reached on the fact that industrial districts generate positive externalities that improve firms' performance (see, among others, Cainelli, 2008a,b) it remains unclear whether the localization of a firm in an industrial district also strengthens its resilience in the face of large and disruptive exogenous supply shocks. This is not a singular question. As observed by Merz et al. (2013), the impact of a disaster depends on hazard and exposure, but also on the vulnerability of the local productive system to business interruptions. The indirect effects of a natural disaster (as the business interruptions analyzed by Kousky, 2014) may be as important as the direct impact.

Our empirical analysis will be conducted on a sample of firms operating in Emilia-Romagna (a region in the North-East of Italy) in the period 2010-2013. This industrialized region was hit by an earthquake sequence of severe intensity between the 20th of May and the 6th of June, 2012. Beside

\footnotetext{
1 See, among others, Skidmore and Toya (2002), Raddatz (2007), Hallegatte and Dumas (2009), Noy (2009), Strobl (2011), Loayza et al. (2012), Ahlerup (2013), Cavallo et al. (2013), Fomby et al. (2013), Belasen and Dai (2014), Cunado and Ferreira (2014), as well as the review of the literature by Cavallo and Noy (2009) and the very recent meta-analysis of the macroeconomic literature by Lazzaroni and van Bergeijk (2014).

2 Barone and Mocetti's (2014) cross-country analyses present other drawbacks. First, natural disasters tend to be geographically concentrated, so that investigations covering extremely large areas may fail capturing very localized effects. Moreover, analyses on aggregated data for the national economy can hardly capture specific channels of shock transmission within and across the nation. As certain countries register a systematically higher number of climatic and geological events (flooding, earthquake and hurricanes), country-level studies may also suffer for the endogeneity of pro-active defensive measures by the authorities and the population. Regional and sub-regional studies are less likely to suffer from this bias, as the exact localization of certain phenomena (say, the epicenter of an earthquake) are difficult to predict and it is unlikely to find highly localized preventive measures. Other empirical problems with cross-country studies may emerge when different natural disasters are pooled together.
} 
some casualties, damages were widespread: historical and private buildings collapsed or suffered large damages, warehouses and factories were partially or totally destroyed.

This recent event has not yet been covered in the literature and this work contributes by exploring its effects on the performance of the local economy. More importantly, this paper is the first, to the best of our knowledge, addressing whether the localization of a firm inside an industrial district worsens or mitigates the effects of an exogenous and disruptive supply shock. Since industrial districts are a fundamental feature of the Italian manufacturing system, our research question is of particular interest for the resilience of many other local systems in the country.

The remainder of the paper is organized as follows. In Section 2, we review the literature on the economic impact of natural disasters and firms' resilience in industrial districts. Section 3 presents the dataset and the econometric methodology. Section 4 discusses the main results. Section 5 concludes.

\section{Related literature}

\subsection{Firms and natural disasters}

The contributions uncovering the impact of natural disasters on the basis of firm-level analyses are very recent. Only few studies have investigated the performance of firms after the realization of a localized major supply shock. ${ }^{3}$

As each contribution focuses on different aspects and implications of disasters (ranging from firm survival to firm performance, from supply network disruptions to localization choices), few studies address comparable research questions on different natural disasters. This prevents from generalizing specific empirical findings to all types of natural disasters and to all countries hit by the same type of shock. Accordingly, we group these studies in terms of country of interest rather than in terms of empirical research question. Possibly because of the importance of natural disasters in a country frequently hit by earthquakes and tsunamis and thanks to the availability of high quality microdata, the majority of the works in this area of research regards Japan. Hence, we start discussing the studies exploring the impact of natural disasters occurred in Japan and subsequently we move to catastrophic events realized in other areas of the world.

Cole et al. (2013) use very detailed data on the plant-level damages produced by the 1995 Kobe earthquake in Japan, estimate the impact of damages on firms' survival and analyze the performance of damaged and non-damaged plants surviving the earthquake. They find that, while highly damaged

3 Leiter et al. (2009) study the impact of floods on European firms, but, given the use of regional aggregated data, their investigation does not fall in the group of firm-level analyses. 
firms face prolonged difficulties and higher risk of exiting, the value added and employment performance of the surviving firms is lower only during the reconstruction period and higher afterwards (while productivity is surprisingly higher in all periods).

Rather than focusing on firm survival and/or performance, some studies have addressed the impact of a natural disaster on the relationship between the firms hit by the shock and others related with them along the supply chain. The role of supply chain networks in the recovery of firms hit by a disaster is investigated by Todo et al. (2013), who focus on the 2011 Great East Japan earthquake. They find that supply chains have two contrasting effects on the firms hit by the shock: on the one hand, supply chains negatively affect the recovery through the firms' higher vulnerability to network disruptions, but, on the other hand, they facilitate the recovery through the support received from trading partners, the easier search for new partners, and the general benefits of agglomeration. The authors find that, all in all, the positive effects of supply chains exceed the negative ones, at least to the extent that firms participate in a variety of supply chains.

Focusing on the firms located outside the damaged areas, Tokui et al. (2017) assess the transmission through supply chain disruptions of the negative effects of the Great East-Japan earthquake. Tokui and co-authors construct an interregional IO table to assess the economic impact of supply chain disruptions in regions of Japan outside the damaged areas and find that the existence of multiple supply chains would have highly mitigated the indirect damage of the disaster, which was instead remarkable. This finding is in line with the conclusions by Carvalho et al. (2014), who look at the transactions (i.e. sales growth) between firms after the tsunami following the Great East-Japan earthquake and show that firms outside the damaged areas encountered serious difficulties in substituting former suppliers and buyers located in the damaged area that exited the business, with cascading effects. The search for new suppliers appears more difficult than that for new customers. The results in Carvalho et al. (2014) as well as Tokui et al. (2017) suggest the existence of bottlenecks in production associated with an imperfect substitutability of intermediate inputs provided by different suppliers.

The Great Kantō earthquake in 1923 is investigated by Imaizumi et al. (2016), who assess whether it had a persistent impact on the spatial distribution of industries in the Tokyo Prefecture. The authors find significant shift in trends in the share and number of workers, though not mean shifts. Moreover, they show that old industrial clusters in the southeast of Tokyo were highly affected whereas newly developing industrial clusters outside the damaged areas faced new opportunities. These findings suggest that both the geographical localization and the position in the supply chain of firms contribute to determine the impact of a natural disaster on firm performance. These results are in contrast with 
those found in the work closest to our investigation, Cole et al. (2015): they show that, although clustering has a negative impact of plant survival probabilities after the 1995 Kobe earthquake in Japan, the location of a firm in a cluster does not impact much on its performance after the shock. This conclusion is in line with the evidence of this work.

As to what concerns the studies focusing on countries other than Japan, we recall Mel et al. (2012), who investigate the business recovery in Sri Lanka after the 2004 tsunami. They find that the firms affected by the disaster lagged behind for a longer period than the unaffected comparable ones and also show that direct aid played a role in the recovery, in particular in the service sector. Similar results on the role of state aid are found by Coelli and Manasse (2014), who look at the impact of the floods occurred in the Italian region of Veneto in 2010. Coelli and Manasse (2014) use a Difference-InDifferences (DID) approach to compare the value added growth of firms exposed and not exposed to the floods and find that: i) after a period of recovery, the affected firms perform better than those not affected by the floods; ii) the contribution of aid transfers in the aftermath of the disaster contributes significantly to the recovery of firms. Vu and Noy (2016) focus on the consequences of natural disasters on Vietnamese firms, and find that a negative impact on retail sales which is however accompanied, albeit only in large urban areas, by increases in firm investment. As in previous studies on Japanese disasters, this suggests that surviving firms invest to overcome temporary, though serious as they be, difficulties.

Focusing on the behavior of multinational enterprises (MNEs) in the face of natural disasters, Hayakawa et al. (2015) analyze the effects of the 2011 flooding in Thailand on the procurement patterns at Japanese affiliates. Only small and directly affected firms lowered their local procurement share, suggesting that natural disasters do not have persistent effects on firms' subjective risks of local procurement. Moreover the adjustment of non-local sources by MNEs depends on their knowledge about suppliers, i.e. their ex-ante preparation of alternative procurement sources. The importance of $e x$ ante conditions is also stressed by Fabling et al. (2014), who analyze the heterogeneous impact of the Canterbury earthquakes in September 2010 and February 2011 on firms across industries and locations. They find that the pre-shock profitability increases the chances of survival in this region of New Zealand. From an empirical point of view, these findings remind of the importance of taking seriously into account confounding factors that may characterize firms both before and after the treatment.

In conclusion, this literature underlines three aspects. First, the firms that are not too seriously damaged and do not have to exit do recover in a relatively short time; this often requires extra investment and some external forms of support. Second, firms located outside the area hit by the shock may be indirectly affected by the disaster through supply disruptions, but this is more relevant for the 
companies that do not have a diversified range of suppliers and customers. The importance of this indirect channel outside the area hit by the shock grows with the intensity and the dispersion of the damages. Third, both the geographical localization and the position in supply chains contribute to determine the impact of a natural disaster on firms' performance.

\subsection{Industrial districts and firms' resilience}

While the role of industrial districts ${ }^{4}$ have been extensively investigated from different perspectives in the economics and management literature, to best of our knowledge, there is no paper focused on the capacity of an industrial district of positively reacting to a short-term external shock such a localized natural disaster. The literature on industrial districts does not offer any clear prediction whether the location of a firm in one of these local productive systems strengthens or weakens its resilience ${ }^{5}$ to large supply shocks. On the one hand, such location may provide the well-known positive advantages associated with agglomeration externalities (typically reflected into higher productivity and profitability, as well as higher rates of survival): in such a case, firms located within a district may cope better with the consequences of a disaster. Moreover, these firms may benefit of greater risk-sharing mechanisms, via interlinking transactions (Dei Ottati, 1994), as shown by Cainelli et al. (2012). Finally, fiscal stimulus and external aid may flow faster towards industrial districts than elsewhere; at least insofar as firms in a district have a vantage position in terms of signaling, lobbying and political connections (Brusco, 1982; Brusco et al., 1996; Brioschi et al., 2002; Cainelli and Zoboli, 2004). ${ }^{6}$

On the other hand, the self-enforcing mechanisms at work in an industrial district may set in motion negative domino effects in the aftermath of a localized disruptive shock. There are different channels through which the cumulative processes associated with localization in a district may reverse and

\footnotetext{
${ }^{4}$ The concept of industrial district dates back to Marshall (1920). In the late 1970s, Becattini (1989) and Brusco (1982) 'revisited' the original Marshallian concept in an effort to explain the socio-economic development in the Third Italy. Although there is no universally accepted notion of industrial district (Cainelli, 2008a), a definition of the "canonical" Italian industrial district model acceptable to most scholars is a "territorial agglomeration of small firms normally specialized in one product or phase of production, held together by interpersonal relationships, by the common social culture of workers, entrepreneurs and politicians surrounded by an industrial atmosphere which facilitates the diffusion of innovation, generating in this way important flows of external economies that are still internal to the local productive systems" (Bianchi, 1994, p.14).

${ }^{5}$ The literature provides alternative definitions of resilience. The ecological approach defines regional resilience as the capacity of a region to move from a possible steady-state path to another (Reggiani et al., 2002). The engineering approach defines regional resilience as the capacity of a region of coming back to a persistent steady-state equilibrium after a shock (Rose, 2004; Fingleton et al., 2012). Recently, the economic geography literature has put attention on a different concept of resilience, which refers - from an evolutionary perspective - to a region's capacity of positively reacting to a short-term external shock (Simmie and Martin, 2010; Martin, 2012). In this paper we follow this perspective.

6 Focusing on aggregated data, Noy (2009) finds that countries with a higher literacy rate, better institutions, and higher degree of openness to trade withstand better the disasters, possibly because they succeed in rapidly mobilizing human and financial resources. Drawing a parallel with these findings, one could expect industrial districts to enjoy a vantage position in terms of local ability for mobilizing resources.
} 
magnify the impact of the shock. The first channel is the transmission of the shock through the supply chain network. Carvalho et al. (2014) find that the sale growth of firms outside an area hit by a large shock are negatively affected by the exiting of upstream and downstream firms in the affected geographical area. ${ }^{7}$ Thus, given the high density of the (productive, technological and commercial) relationships among firms in industrial districts, the shock transmission along the supply chain may be stronger within these local systems than in non-district areas. ${ }^{8}$ As shown by Todo et al. (2013) and Tokui et al. (2017), firms may indeed benefit from enjoying a geographically diversified network of suppliers and clients, because this facilitates the substitution of damaged partners after a localized shock. Another potential channel through which firms in an industrial district may be more severely hit pertains to the financial realm: if banks have localized lending relationships, a disaster may negatively impact on the provision of external finance to the firms located in the affected area. ${ }^{9}$ Finally, the location in an industrial district may magnify the impact of a disruptive supply shock because of the relative larger importance of damages to local infrastructures, at least to the extent that natural amenities contribute to agglomeration in industrial districts.

As theory does not tell whether the location in an industrial district makes a firm more or less resilient in the face of a disruptive exogenous supply shock, new empirical analyses are of great importance to improve our understanding of how natural disasters hit firms and whether their localization within a district makes a difference or not for their performance.

\section{Data and empirical approach}

\subsection{Data}

Between 20 May and 6 June 2012, the Emilia-Romagna region, located in the North-East of Italy, was hit by a sequence of severe earthquakes. The first one (magnitude 5.9) struck close to Bologna and its epicenter was in the area near the town Finale Emilia. This was followed by two aftershocks of lower magnitude (still above 5). A magnitude 5.8 earthquake hit the same area on 29 May 2012, followed by another sequence of earthquakes. Two aftershocks hit again: the first on 3 June and the second on 6 June.

7 The impact on downstream firms is shown to be at work for the firms linked both directly and indirectly. 8 Such hypothesis is consistent with the conclusions by Henriet et al. (2012), who, via a simulation analysis based on inputoutput tables, show that clusters hit by a shock suffer less when they are not too concentrated and that the resilience of the economic system to natural disasters is higher when supply chains are localized and each cluster is isolated from external disasters.

9 As shown for Japan by Uchida et al. (2013), this may not be the case if damaged banks receive external financial support from either the government or other private investors. Hosono et al. (2016) show that the lending capacity of banks located in an area affected by a disaster is reduced and impacts on firms' investment, even when firms are located outside such area. 
This natural disaster caused serious damages to private and public buildings, as well as to productive units. Figure 1 offers a graphical representation of the impact of the earthquake on 29 May 2012 in the Emilia Romagna region.

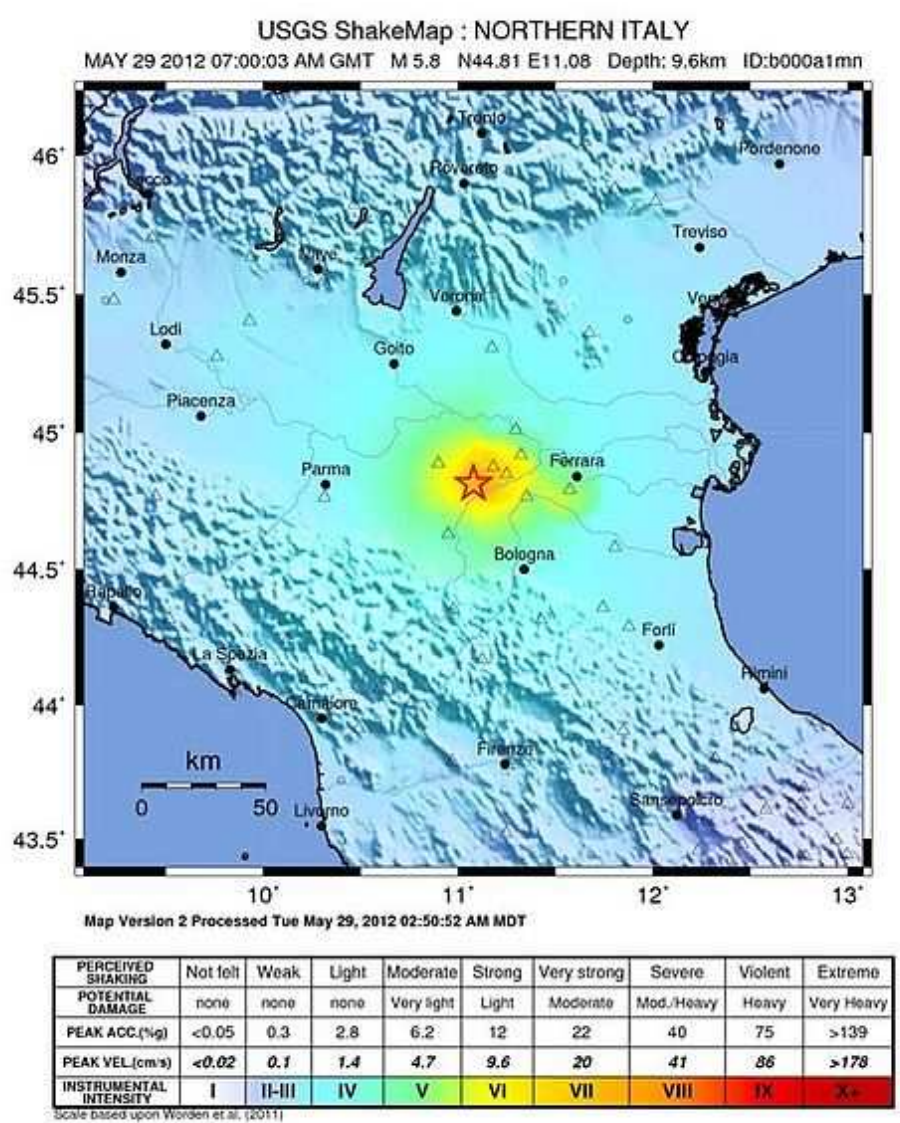

Source: Wikimedia.

Figure 1: A map of the Emilia-Romagna earthquake in 2012

As shown in Figure 1, the earthquake was powerful but highly localized as only light shaking was perceived outside the areas closest to the epicenter. Given the high manufacturing density in EmiliaRomagna and the presence of several industrial districts (Brusco et al., 1996), this event represents a natural experiment which can be used to assess whether the location of firms in an industrial district enhances or weakens their economic resilience.

To tackle this issue, we use information drawn from the Bureau van Dijk database. Specifically, we construct a sample of about 26,000 firms (in manufacturing and KIBS) located in Emilia-Romagna during the period 2010-2013. As summarized in Tables 1 and 2, one third of these firms are located in 
an industrial district and less than $10 \%$ are placed in areas hit by the earthquake. More importantly, the Tables show that not all the firms hit by the earthquake are in an industrial district and not all the firms located within an industrial district are placed in areas hit by the disaster. This allows us to adopt different econometric methods to identify the differentiated impact of the earthquake across firms and districts.

In this work we focus on a number of proxies for firm's performance: turnover; tangible assets; bank debt/sales ratio; value of production; Return On Sales (ROS), i.e. EBIT/net Sales; Return On Equity (ROE), i.e. net income/equity.

As we aim at detecting the earthquake impact on firms' performance and to differentiate the analysis according to whether firms are located in industrial districts or not, for each firm we need more than one observation: one before the earthquake and one afterwards. Since the earthquake hit EmiliaRomagna in mid-2012, it is not theoretically clear whether the pre-shock performances (calculated as the average values in the years 2010-2011) are to be compared either with the 2012 end-of-year values or with those in 2013. According to previous contributions, we expect to find stronger results for the 2012 because the firms that survive a disaster tend to absorb the shock rather quickly. By running the estimations for both 2012 and 2013, we shall test this intuition and indirectly assess both the short and longer effects of the disaster on the surviving firms.

Table 1: Breakdown of the sample of firms by earthquake and district

\begin{tabular}{llll}
\hline \hline \multirow{2}{*}{ Industrial district } & \multicolumn{2}{l}{ Earthquake } & \multirow{2}{*}{ Total } \\
\cline { 2 - 3 } & No & Yes & \\
\hline No & 14,937 & 1,886 & 16,823 \\
Yes & 6,940 & 2,522 & 9,462 \\
\hline Total & 21,877 & 4,408 & 26,285 \\
\hline \hline
\end{tabular}


Table 2: Breakdown of the sample of firms by sector, earthquake and district

\begin{tabular}{|c|c|c|c|c|c|c|c|c|c|c|c|c|c|c|}
\hline \multirow{2}{*}{$\begin{array}{c}\text { ATECO } \\
\text { 2-digit }\end{array}$} & \multicolumn{3}{|c|}{ no earthquake- no district } & \multicolumn{3}{|c|}{ earthquake-no district } & \multicolumn{3}{|c|}{ no earthquake-district } & \multicolumn{3}{|c|}{ Earthquake-district } & \multicolumn{2}{|c|}{ Total } \\
\hline & No. & $\mathrm{Col} \%$ & Row \% & No. & $\mathrm{Col} \%$ & Row \% & No. & $\mathrm{Col} \%$ & Row \% & No. & $\mathrm{Col} \%$ & Row $\%$ & No. & $\mathrm{Col} \%$ \\
\hline 10 & 542 & 3.6 & 50.7 & 52 & 2.8 & 4.9 & 411 & 5.9 & 38.4 & 65 & 2.6 & 6.1 & 1070 & 4.1 \\
\hline 11 & 36 & 0.2 & 42.4 & 4 & 0.2 & 4.7 & 34 & 0.5 & 40.0 & 11 & 0.4 & 12.9 & 85 & 0.3 \\
\hline 13 & 39 & 0.3 & 18.8 & 14 & 0.7 & 6.7 & 45 & 0.6 & 21.6 & 110 & 4.4 & 52.9 & 208 & 0.8 \\
\hline 14 & 173 & 1.2 & 28.3 & 72 & 3.8 & 11.8 & 111 & 1.6 & 18.2 & 255 & 10.1 & 41.7 & 611 & 2.3 \\
\hline 15 & 99 & 0.7 & 63.5 & 9 & 0.5 & 5.8 & 40 & 0.6 & 25.6 & 8 & 0.3 & 5.1 & 156 & 0.6 \\
\hline 16 & 147 & 1.0 & 55.7 & 23 & 1.2 & 8.7 & 62 & 0.9 & 23.5 & 32 & 1.3 & 12.1 & 264 & 1.0 \\
\hline 17 & 80 & 0.5 & 48.5 & 13 & 0.7 & 7.9 & 46 & 0.7 & 27.9 & 26 & 1.0 & 15.8 & 165 & 0.6 \\
\hline 18 & 234 & 1.6 & 59.8 & 22 & 1.2 & 5.6 & 85 & 1.2 & 21.7 & 50 & 2.0 & 12.8 & 391 & 1.5 \\
\hline 19 & 2 & 0.0 & 25.0 & 0 & 0.0 & 0.0 & 4 & 0.1 & 50.0 & 2 & 0.1 & 25.0 & 8 & 0.0 \\
\hline 20 & 174 & 1.2 & 58.8 & 32 & 1.7 & 10.8 & 77 & 1.1 & 26.0 & 13 & 0.5 & 4.4 & 296 & 1.1 \\
\hline 21 & 17 & 0.1 & 48.6 & 6 & 0.3 & 17.1 & 6 & 0.1 & 17.1 & 6 & 0.2 & 17.1 & 35 & 0.1 \\
\hline 22 & 226 & 1.5 & 46.0 & 40 & 2.1 & 8.1 & 142 & 2.0 & 28.9 & 83 & 3.3 & 16.9 & 491 & 1.9 \\
\hline 23 & 368 & 2.5 & 67.3 & 17 & 0.9 & 3.1 & 136 & 2.0 & 24.9 & 26 & 1.0 & 4.8 & 547 & 2.1 \\
\hline 24 & 63 & 0.4 & 46.3 & 21 & 1.1 & 15.4 & 39 & 0.6 & 28.7 & 13 & 0.5 & 9.6 & 136 & 0.5 \\
\hline 25 & 1392 & 9.3 & 50.3 & 259 & 13.7 & 9.4 & 752 & 10.8 & 27.2 & 366 & 14.5 & 13.2 & 2769 & 10.5 \\
\hline 26 & 196 & 1.3 & 49.5 & 40 & 2.1 & 10.1 & 123 & 1.8 & 31.1 & 37 & 1.5 & 9.3 & 396 & 1.5 \\
\hline 27 & 268 & 1.8 & 51.8 & 57 & 3.0 & 11.0 & 139 & 2.0 & 26.9 & 53 & 2.1 & 10.3 & 517 & 2.0 \\
\hline 28 & 1184 & 7.9 & 52.7 & 195 & 10.3 & 8.7 & 614 & 8.8 & 27.3 & 254 & 10.1 & 11.3 & 2247 & 8.5 \\
\hline 29 & 94 & 0.6 & 46.8 & 19 & 1.0 & 9.5 & 61 & 0.9 & 30.3 & 27 & 1.1 & 13.4 & 201 & 0.8 \\
\hline 30 & 81 & 0.5 & 70.4 & 8 & 0.4 & 7.0 & 25 & 0.4 & 21.7 & 1 & 0.0 & 0.9 & 115 & 0.4 \\
\hline 31 & 135 & 0.9 & 46.4 & 14 & 0.7 & 4.8 & 126 & 1.8 & 43.3 & 16 & 0.6 & 5.5 & 291 & 1.1 \\
\hline 32 & 210 & 1.4 & 61.4 & 23 & 1.2 & 6.7 & 70 & 1.0 & 20.5 & 39 & 1.5 & 11.4 & 342 & 1.3 \\
\hline 62 & 683 & 4.6 & 62.1 & 78 & 4.1 & 7.1 & 272 & 3.9 & 24.7 & 67 & 2.7 & 6.1 & 1100 & 4.2 \\
\hline 63 & 549 & 3.7 & 63.2 & 50 & 2.7 & 5.8 & 215 & 3.1 & 24.8 & 54 & 2.1 & 6.2 & 868 & 3.3 \\
\hline 68 & 5053 & 33.8 & 60.2 & 540 & 28.6 & 6.4 & 2124 & 30.6 & 25.3 & 671 & 26.6 & 8.0 & 8388 & 31.9 \\
\hline 69 & 323 & 2.2 & 64.0 & 27 & 1.4 & 5.3 & 141 & 2.0 & 27.9 & 14 & 0.6 & 2.8 & 505 & 1.9 \\
\hline 70 & 997 & 6.7 & 65.9 & 81 & 4.3 & 5.4 & 360 & 5.2 & 23.8 & 74 & 2.9 & 4.9 & 1512 & 5.8 \\
\hline 71 & 580 & 3.9 & 60.2 & 69 & 3.7 & 7.2 & 263 & 3.8 & 27.3 & 51 & 2.0 & 5.3 & 963 & 3.7 \\
\hline 72 & 105 & 0.7 & 62.1 & 16 & 0.8 & 9.5 & 42 & 0.6 & 24.9 & 6 & 0.2 & 3.6 & 169 & 0.6 \\
\hline 73 & 340 & 2.3 & 62.7 & 36 & 1.9 & 6.6 & 145 & 2.1 & 26.8 & 21 & 0.8 & 3.9 & 542 & 2.1 \\
\hline 74 & 546 & 3.7 & 60.9 & 49 & 2.6 & 5.5 & 230 & 3.3 & 25.7 & 71 & 2.8 & 7.9 & 896 & 3.4 \\
\hline Total & 14937 & 100.0 & 56.8 & 1886 & 100.0 & 7.2 & 6940 & 100.0 & 26.4 & 2522 & 100.0 & 9.6 & 26285 & 100 \\
\hline
\end{tabular}

\subsection{Methodology}

The aim of this section is to illustrate our empirical methodology. We address wo research questions: i) the impact of the earthquake sequence on the firms' performance after the shock; ii) the differential impact of the earthquake according to the localization of the firms inside or outside an industrial district.

\subsubsection{The average impact of the earthquake sequence}

To estimate the effect of the earthquake on firms' performance we employ two alternative methods: (i) Difference-In-Differences (DID); (ii) Propensity Score Matching (PSM) on the variables of interest in levels and first-differences (measured both before and after the earthquake).

These two methods require that some conditions are fulfilled. The most important is the presence of a reliable control group, that is, a subsample of firms not hit by the earthquake. The second condition is that the selection of the firms into treatment (i.e., being located in an area hit by the earthquake) is independent from the characteristics of firms that also affect their performance. In other words, these 
methods require the existence of the same unit of observation before and after the treatment. This implies that we focus only on surviving firms.

The DID approach compares the change in the performance of firms located in an area hit by the earthquake with the change in the performance of firms placed in a territory not affected by the disaster, after controlling for a number of firm-specific and area-specific characteristics.

Assuming that $y_{i t}$ is the performance variable of interest (e.g, production, value added, etc.) for the firm $i$ in period $t$, the impact of the earthquake can be captured by estimating either:

$$
y_{i t}=a_{i}+\beta_{0} t_{t}+\beta_{1} e_{t}+\beta_{2} e_{i} t_{t}+u_{i t}
$$

or

$$
\Delta y_{i}=\delta_{0}+\delta_{1} e_{i}+\delta_{2} X_{i}+v_{i}
$$

where $t \in\{0,1\}$ is the pre-post earthquake period, $t_{t}$ is the time dummy (equal to 1 if $t=1$ ), $e_{i}$ is the earthquake dummy (equal to 1 if the firm is located in an area hit by the earthquake in period 1 and 0 otherwise), and $X_{i}$ contains firm-level exogenous controls (sector, year of incorporation, etc.). The main difference between equation (1) and (2) is that the latter, by differentiating, removes any time-invariant unit-specific effects on the level but allows to consider firm-specific controls possibly affecting the rate of change. The former can take two forms: a pooled estimation or a fixed-effect panel estimation to absorb the impact of any firm-specific time-invariant controls.

The variable of interest in equation (1) is the term $e_{i} t$, which captures the average effect of the disaster on the level of the performance of interest, after controlling for $X_{i}$. The variable of interest in equation (2) is the dummy $e_{i}$, that is used to assess the average effect of the treatment on the change of the performance variable of the treated firms.

When there are reasons to believe that the treatment might not be randomly distributed across the units and that there might be confounding factors affecting the DID estimator, an alternative approach to quantify the effects of the earthquake on the firms is Propensity Score Matching (PSM). PSM controls for confounding factors in the estimation of the impact of the treatment by ensuring that the comparison is performed using treated and control units that are as similar as possible. Three steps need to be done: i) the pre-treatment firm characteristics are summarized in a single variable (the propensity score) by means of a probit/logit estimation; ii) similar treated and control firms are matched; iii) the average effect of the treatment on the treated is calculated as the average difference between the values of the variable of interest for the treated firms and the control firms in each pair of matched firms. More and better are the variables used to calculate the propensity scores, more efficient is the removal of 
confounding factors. In order to work, this approach requires that the sample contains enough pairs of treated and control units with the same propensity score.

The nature of the shock suggests not worrying about problems of self-selection into treatment: before the disaster, the region was considered as having very low systemic risk and no firm chose its location on the basis of the probabilities of being hit by an earthquake. Nonetheless, given that the geographical distribution of firms operating in different industries is neither homogeneous nor random, one may want to control for the possibility that the average treatment effect may (statistically) reflect sector-related confounding factors.

\subsubsection{The differentiated effect of industrial districts}

These two methods capture the average effect of the treatment on the treated, that is, the average impact of the earthquake on the firms located in areas directly affected. This is the first issue that we deal with. The second research question regards the differentiated impact of the earthquake on firms that are located in industrial districts with respect to those that are not.

Generally, firms choose where to locate: their being inside or outside an industrial district is likely correlated with their characteristics. Accordingly, one cannot use the same approach also to address the differentiated effect of the earthquake across geographical areas that are and are not industrial districts. This forces us to work on the previous specification and insert a set of dummies and interacting terms to estimate the differential impact of a unique treatment, i.e. the earthquake.

$$
y_{i t}=c_{i}+\gamma_{0} t_{t}+\gamma_{1} d_{i} t_{t}+\gamma_{2} e_{i} t_{t}+\gamma_{3} e_{i} d_{i} t_{t}+\varepsilon_{i t}
$$

or

$$
\Delta y_{i}=\pi_{0}+\pi_{1} d_{i}+\pi_{2} e_{i}+\pi_{3} e_{i} d_{i}+\pi_{4} X_{i}+v_{i}
$$

where $d_{i}$ is a district dummy (equal to 1 if the firm belongs to an industrial district and 0 otherwise).

The variables of interest in equation (3) are the term $e_{i} d_{i} t_{t}$, capturing the district-related difference in the treatment effect on the outcome variable $y$, and the term $e_{i} t_{t}$, that assesses the average treatment effect on the treated firms for the performance of interest. In equation (4), the same holds, respectively, for the interaction dummy $e_{i} d_{i}$ and the dummy $e_{i}$.

\section{Results}

Table 3 reports the average impact of the earthquake on the performance of firms located in the affected areas, with no distinction between industrial districts and other areas. 
For the year 2012, we obtain consistent estimates from the different estimators adopted: OLS pooled DID, panel fixed-effects DID, first-differences DID, and PSM. The earthquake, on average, reduces turnover, production, value added, and ROS. These estimates are all statistically significant for the OLS estimates in levels and for the OLS and PSM in first differences; only ROS seems instead significantly affected by the disaster according to the PSM in levels. The panel fixed-effects and the first-differences estimations (OLS and PSM) suggest that the debt over sales ratio significantly grows more in the firms located in the areas affected by the earthquake. Intuitively, these results have an economic sense. Firms affected by the earthquake performed, on average, worse than the others but they survived also thanks to expanding their debt. Notably, the debt variable is significant only when fixed-effects or firstdifferences are considered: this suggests that there is a differential variation in the accumulation of debt rather than a differential level-effect.

For the year 2013, only the variation in the debt over sales ratio remains statistically significant in fixed-effects or first-differences panels, as well as PSM. Besides this, there is also some weak evidence of a differentiated growth in the volume of tangibles, whereby hit firms accumulated more tangibles. In fact, had we looked exclusively at 2013, we would have concluded that the earthquake had no impact on the firms located in the areas affected by the disaster. In fact, as the analysis in 2012 shows, firms were affected but did also recover fast (this result is in line with the other studies reviewed before). The possibility of tapping credit seems particularly important for firms to bear such large a shock.

Having established the average effect of the earthquake on the performance of the surviving firms, we move to our second research question, that is, whether the location of a firm in an industrial district exacerbates or mitigates the impact of the earthquake. Our evidence (Tables 4-7) suggests that there is a negative impact of the earthquake on the activity and efficiency of firms. This effect is higher in the short-term (2012) for the industrial district firms. This is true for production, turnover, value added, and ROS. Similarly, the increase in firms' indebtedness (debt/sales) is particularly significant for the firms located in these local productive systems.

This finding supports the hypothesis that industrial districts may exhibit lower resilience in the face of a large and disruptive supply shock because the cumulative processes associated with localization externalities may reverse and magnify the negative impact of adverse phenomena. The shock transmission may work through three different mechanisms: (i) the supply chains (Carvalho et al., 2014); (ii) the weakening of agglomeration externalities, (iii) the existence of local risk-sharing mechanisms that increase the probability of mass defaults (Cainelli et al., 2012). Our results do not support the hypothesis that industrial district firms may be affected by a localized credit crunch as they do manage to increase their debt levels. 
Table 3: Estimation results

\begin{tabular}{|c|c|c|c|c|c|c|c|c|c|c|}
\hline \multirow{4}{*}{$\begin{array}{l}\text { Dependent } \\
\text { variable }\end{array}$} & \multicolumn{6}{|c|}{ Level } & \multicolumn{4}{|c|}{ First difference: $2010 / 11-$} \\
\hline & \multicolumn{4}{|c|}{ Pooled estimation } & \multicolumn{2}{|c|}{ Panel FE: 2010/11- } & & & & \\
\hline & \multicolumn{2}{|c|}{2012} & \multicolumn{2}{|c|}{2013} & \multirow[t]{2}{*}{2012} & \multirow[t]{2}{*}{2013} & \multicolumn{2}{|c|}{2012} & \multicolumn{2}{|c|}{2013} \\
\hline & OLS & PSM & OLS & PSM & & & OLS & PSM & OLS & PSM \\
\hline $\ln$ (turnover) & $-.0485^{*}$ & -.0033 & -.0128 & .0318 & $-.0281^{* *}$ & -.0003 & $-.0225^{* * *}$ & $-.0223^{*}$ & .0150 & .0138 \\
\hline & $(.0265)$ & $(.0362)$ & $(.0272)$ & $(.0367)$ & $(.0118)$ & $(.0150)$ & $(.0114)$ & $(.0123)$ & $(.0145)$ & $(.0158)$ \\
\hline $\ln$ (tangibles) & $\begin{array}{l}-.0060 \\
(.0356)\end{array}$ & $\begin{array}{l}.0036 \\
(.0457)\end{array}$ & $\begin{array}{l}.0289 \\
(.0365)\end{array}$ & $\begin{array}{l}.0382 \\
(.0463)\end{array}$ & $\begin{array}{l}.0015 \\
(.0117)\end{array}$ & $\begin{array}{l}.0299 \\
(.0158)\end{array}$ & $\begin{array}{l}.0010 \\
(.0117)\end{array}$ & $\begin{array}{l}-.0004 \\
(.0126)\end{array}$ & $\begin{array}{l}.0301^{*} \\
(.0164)\end{array}$ & $\begin{array}{l}.0295^{*} \\
(.01750)\end{array}$ \\
\hline debt/sales & $\begin{array}{l}-.5790 \\
(.4395)\end{array}$ & $\begin{array}{l}-.3758 \\
(.4747)\end{array}$ & $\begin{array}{l}-.0551 \\
(.4508)\end{array}$ & $\begin{array}{l}-.0487 \\
(.4792)\end{array}$ & $\begin{array}{l}.8761^{* * * *} \\
(.2646)\end{array}$ & $\begin{array}{l}1.107^{* * * *} \\
(.3302)\end{array}$ & $\begin{array}{l}.7413^{* * * *} \\
(.2807)\end{array}$ & $\begin{array}{l}.7469^{* * * *} \\
(.2967)\end{array}$ & $\begin{array}{l}1.012^{* * * *} \\
(.3403)\end{array}$ & $\begin{array}{l}.9642^{* * * *} \\
(.3579)\end{array}$ \\
\hline $\ln$ (value-added) & $\begin{array}{l}-.0573^{\text {承 }} \\
(.0285)\end{array}$ & $\begin{array}{l}-.0377 \\
(.03659)\end{array}$ & $\begin{array}{l}-.0410 \\
(.0292)\end{array}$ & $\begin{array}{l}-.0210 \\
(.0374)\end{array}$ & $\begin{array}{l}-.0471^{\text {**** }} \\
(.0129)\end{array}$ & $\begin{array}{l}-.0094 \\
(.0151)\end{array}$ & $\begin{array}{l}-.0451^{\text {*承水 }} \\
(.0134)\end{array}$ & $\begin{array}{l}-.0442^{\text {**** }} \\
(.0142)\end{array}$ & $\begin{array}{l}-.0051 \\
(.0151)\end{array}$ & $\begin{array}{l}-.0065 \\
(.0161)\end{array}$ \\
\hline $\ln ($ production) & $\begin{array}{l}-.0563^{* * *} \\
(.0259)\end{array}$ & $\begin{array}{l}-.0117 \\
(.0354)\end{array}$ & $\begin{array}{l}-.0152 \\
(.0266)\end{array}$ & $\begin{array}{l}.0301 \\
(.0358)\end{array}$ & $\begin{array}{l}-.0368^{* * *} \\
(.01108)\end{array}$ & $\begin{array}{l}.0002 \\
(.0140)\end{array}$ & $\begin{array}{l}-.0282^{\text {*.*k }} \\
(.0108)\end{array}$ & $\begin{array}{l}-.0289^{* * *} \\
(.0115)\end{array}$ & $\begin{array}{l}.0136 \\
(.0137)\end{array}$ & $\begin{array}{l}.0123 \\
(.0147)\end{array}$ \\
\hline ROE & $\begin{array}{l}.3185 \\
(.5300)\end{array}$ & $\begin{array}{l}.2943 \\
(.5623)\end{array}$ & $\begin{array}{l}.9978^{* * *} \\
(.5004)\end{array}$ & $\begin{array}{l}1.0563^{* *} \\
(.5366)\end{array}$ & $\begin{array}{l}-.8054 \\
(.5366)\end{array}$ & $\begin{array}{l}.1686 \\
(.5606)\end{array}$ & $\begin{array}{l}-.4791 \\
(.5739)\end{array}$ & $\begin{array}{l}-.3078 \\
(.5970)\end{array}$ & $\begin{array}{l}.3343 \\
(.5753)\end{array}$ & $\begin{array}{l}.4914 \\
(.6102)\end{array}$ \\
\hline ROS & 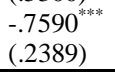 & 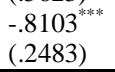 & $\begin{array}{l}-.3024 \\
(.2319)\end{array}$ & $\begin{array}{l}-.4231^{*} \\
(.2450)\end{array}$ & $\begin{array}{l}-.6227^{\text {***.* }} \\
(.2148)\end{array}$ & $\begin{array}{l}.0589 \\
(.2350)\end{array}$ & 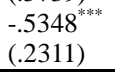 & $\begin{array}{l}-.5658^{* \ldots * k} \\
(.2426)\end{array}$ & $\begin{array}{l}.0930 \\
(.2457)\end{array}$ & $\begin{array}{l}.0468 \\
(.2588) \\
\end{array}$ \\
\hline
\end{tabular}

The coefficient reported is the one attached to the earthquake dummy, for each dependent variable and specification. Robust standard errors in parenthesis. Controls for sector (4-digit), incorporation year and district included in OLS and PSM. Significance at: 1\%;5\%;10\%.

Table 4: Earthquake effect inside/outside districts: results

\begin{tabular}{|c|c|c|c|}
\hline \multirow[t]{2}{*}{ Dependent variable } & \multirow[t]{2}{*}{ Regressor } & \multicolumn{2}{|c|}{ Years: 2010/11- } \\
\hline & & 2012 & 2013 \\
\hline \multirow[t]{4}{*}{$\overline{\Delta \ln (\text { turnover })}$} & District dummy (d) & $-.0039(.0109)$ & $-.0149(.0138)$ \\
\hline & Earthquake dummy (e) & $-.0094(.0154)$ & $.0206(.0200)$ \\
\hline & $e \cdot d$ & $-.0254(.0225)$ & $-.0109(.0289)$ \\
\hline & $\mathrm{e}+\mathrm{e} \cdot \mathrm{d}$ & $-.0348^{* * *}(.0166)$ & $.0100(.0211)$ \\
\hline \multirow[t]{4}{*}{$\overline{\Delta \ln (\text { tangibles })}$} & District dummy (d) & $.0103(.0107)$ & $.0049(.0142)$ \\
\hline & Earthquake dummy (e) & $.0055(.0155)$ & $.0334(.0230)$ \\
\hline & $\mathrm{e} \cdot \mathrm{d}$ & $-.0087(.0228)$ & $-.0065(.0322)$ \\
\hline & $e+e \cdot d$ & $-.0033(.0170)$ & $.0269(.0229)$ \\
\hline \multirow[t]{4}{*}{$\Delta \mathrm{debt} / \mathrm{sales}$} & District dummy (d) & $.0025(.2484)$ & $-.0100(.3038)$ \\
\hline & Earthquake dummy (e) & $.0711(.3773)$ & $.1863(.4548)$ \\
\hline & $\mathrm{e} \cdot \mathrm{d}$ & $1.336^{* *}(.5538)$ & $1.668^{* *}(.6683)$ \\
\hline & $\mathrm{e}+\mathrm{e} \cdot \mathrm{d}$ & $1.407^{* * * *}(.4103)$ & $1.855^{* * * *}(.4982)$ \\
\hline \multirow[t]{4}{*}{$\overline{\Delta \ln (\text { value added })}$} & District dummy (d) & $-.0026(.0115)$ & $.0016(.0136)$ \\
\hline & Earthquake dummy (e) & $-.0263(.0185)$ & $.0042(.0212)$ \\
\hline & $\mathrm{e} \cdot \mathrm{d}$ & $-.0366(.0262)$ & $-.0236(.0299)$ \\
\hline & $e+e \cdot d$ & $-.0629^{* * * *}(.0190)$ & $-.0194(.0216)$ \\
\hline
\end{tabular}

Robust standard errors in parenthesis. Significance at: $1 \% ; 5 \% ; 10 \%$.Regressions include sector (4-digit) dummies and year of incorporation. 
Table 5: Earthquake effect inside/outside districts: results

\begin{tabular}{|c|c|c|c|}
\hline \multirow[t]{2}{*}{ Dependent variable } & \multirow[t]{2}{*}{ Regressor } & \multicolumn{2}{|c|}{ Years: 2010/11- } \\
\hline & & 2012 & 2013 \\
\hline \multirow[t]{4}{*}{$\overline{\Delta \ln (\text { production})}$} & District dummy (d) & $-.0020(.0102)$ & $-.0054(.0129)$ \\
\hline & Earthquake dummy (e) & $-.0097(.0150)$ & $.0230(.0189)$ \\
\hline & $\mathrm{e} \cdot \mathrm{d}$ & $-.0358(.0213)$ & $-.0183(.0270)$ \\
\hline & $e+e \cdot d$ & $-.0455(.0153)$ & $.0047(.0196)$ \\
\hline \multirow[t]{4}{*}{$\overline{\Delta \mathrm{ROE}}$} & District dummy (d) & $-.3928(.4786)$ & $.9712(.4959)$ \\
\hline & Earthquake dummy (e) & $-.5294(.8098)$ & $1.139(.7810)$ \\
\hline & $\mathrm{e} \cdot \mathrm{d}$ & $.0980(1.123)$ & $-1.554(1.123)$ \\
\hline & $e+e \cdot d$ & $-.4314(.7963)$ & $-.4155(.8241)$ \\
\hline \multirow[t]{4}{*}{$\overline{\Delta \mathrm{ROS}}$} & District dummy (d) & $-.0418(.1965)$ & $-.0097(.2172)$ \\
\hline & Earthquake dummy (e) & $-.3433(.3264)$ & $.3435(.3516)$ \\
\hline & $\mathrm{e} \cdot \mathrm{d}$ & $-.3730(.4508)$ & $-.4895(.4797)$ \\
\hline & $\mathrm{e}+\mathrm{e} \cdot \mathrm{d}$ & $-.7163(.3192)$ & $-.1460(.3354)$ \\
\hline
\end{tabular}

Robust standard errors in parenthesis. Significance at: $1 \% ; 5 \% ; 10 \%$.Regressions include sector (4-digit) dummies and year of incorporation.

Table 6: Earthquake effect insideloutside districts: FE estimator

\begin{tabular}{|c|c|c|c|}
\hline \multirow{2}{*}{ Dependent variable } & \multirow[t]{2}{*}{ Regressor } & \multicolumn{2}{|c|}{ Years: 2010/11- } \\
\hline & & 2012 & 2013 \\
\hline \multirow[t]{4}{*}{$\ln ($ turnover) } & District dummy $(\mathrm{d}) \cdot$ Time dummy $(\mathrm{t})$ & $.0026(.0104)$ & $-.0056(.0136)$ \\
\hline & Earthquake dummy $(\mathrm{e}) \cdot$ Time dummy $(\mathrm{t})$ & $-.0083(.0175)$ & $.0186(.0197)$ \\
\hline & $\underline{e} \cdot \mathrm{d} \cdot \mathrm{t}$ & $-.0358(.0241)$ & $-.0304(.0286)$ \\
\hline & $\mathrm{e} \cdot \mathrm{t}+\mathrm{e} \cdot \mathrm{d} \cdot \mathrm{t}$ & $-.0441^{* * * *}(.0166)$ & $-.0118(.0207)$ \\
\hline \multirow[t]{4}{*}{$\ln$ (tangibles) } & District dummy $(\mathrm{d}) \cdot$ Time dummy $(\mathrm{t})$ & $.0167(.0106)$ & $.0155(.0141)$ \\
\hline & Earthquake dummy $(\mathrm{e}) \cdot$ Time dummy $(\mathrm{t})$ & $.0048(.0154)$ & $.0322(.0234)$ \\
\hline & $\underline{e \cdot d \cdot t}$ & $-.0130(.0226)$ & $-.0107(.0324)$ \\
\hline & $\mathrm{e} \cdot \mathrm{t}+\mathrm{e} \cdot \mathrm{d} \cdot \mathrm{t}$ & $-.0082(.0166)$ & $.0214(.0223)$ \\
\hline \multirow[t]{4}{*}{ debt/sales } & District dummy $(\mathrm{d}) \cdot$ Time dummy $(\mathrm{t})$ & $.0735(.2424)$ & $.0583(.2945)$ \\
\hline & Earthquake dummy $(\mathrm{e}) \cdot$ Time dummy $(\mathrm{t})$ & $.1706(.3697)$ & $.2849(.4767)$ \\
\hline & $\mathrm{e} \cdot \mathrm{d} \cdot \mathrm{t}$ & $1.229(.5424)$ & $1.477^{* * * *}(.6715)$ \\
\hline & $\mathrm{e} \cdot \mathrm{t}+\mathrm{e} \cdot \mathrm{d} \cdot \mathrm{t}$ & $1.400^{\text {****** }}(.3968)$ & $1.761^{* * * * *}(.4802)$ \\
\hline \multirow[t]{4}{*}{$\ln$ (value-added) } & District dummy $(\mathrm{d}) \cdot$ Time dummy $(\mathrm{t})$ & $.0044(.0114)$ & $.0099(.0134)$ \\
\hline & Earthquake dummy $(\mathrm{e}) \cdot$ Time dummy $(\mathrm{t})$ & $-.0253(.0185)$ & $.0046(.0211)$ \\
\hline & $\underline{e \cdot d \cdot t}$ & $-.0401(.0261)$ & $-.0291(.0296)$ \\
\hline & $\overline{e \cdot t+e \cdot d \cdot t}$ & $-.0655^{* * *}(.0184)$ & $-.0245(.0208)$ \\
\hline
\end{tabular}

Robust standard errors in parenthesis. Significance at: $1 \% ; 5 \% ; 10 \%$. 
Table 7: Earthquake effect insideloutside districts: FE estimator

\begin{tabular}{|c|c|c|c|}
\hline \multicolumn{2}{|c|}{ Dependent variable Regressor } & \multicolumn{2}{|c|}{ Years: 2010/11- } \\
\hline & & 2012 & 2013 \\
\hline \multirow[t]{4}{*}{$\overline{\ln (\text { production })}$} & District dummy $(\mathrm{d}) \cdot$ Time dummy $(\mathrm{t})$ & $.0019(.0101)$ & $.0013(.0128)$ \\
\hline & Earthquake dummy $(\mathrm{e}) \cdot$ Time dummy $(\mathrm{t})$ & $-.0116(.0149)$ & $.0204(.0188)$ \\
\hline & $\mathrm{e} \cdot \mathrm{d} \cdot \mathrm{t}$ & $-.0451^{* *}(.0210)$ & $-.0359(.0268)$ \\
\hline & $\mathrm{e} \cdot \mathrm{t}+\mathrm{e} \cdot \mathrm{d} \cdot \mathrm{t}$ & $-.0566^{* * *}(.0148)$ & $-.0155(.0198)$ \\
\hline \multirow[t]{4}{*}{$\mathrm{ROE}$} & District dummy (d) $\square$ Time dummy (t) & $.2851(.4725)$ & $1.046^{* * *}(.4912)$ \\
\hline & $\begin{array}{l}\text { Earthquake dummy (e) } \square \text { Time dummy } \\
\text { (t) }\end{array}$ & $-.6541(.7976)$ & $1.038(.7755)$ \\
\hline & $\mathrm{e} \cdot \mathrm{d} \cdot \mathrm{t}$ & $-.1384(1.103)$ & $-1.979^{*}(1.111)$ \\
\hline & $e \cdot t+e \cdot d \cdot t$ & $-.7925(.7616)$ & $-.9412(.7955)$ \\
\hline \multirow[t]{4}{*}{$\overline{\mathrm{ROS}}$} & District dummy $(\mathrm{d}) \cdot$ Time dummy $(\mathrm{t})$ & $.0037(.1922)$ & $.0920(.2112)$ \\
\hline & Earthquake dummy $(\mathrm{e}) \cdot$ Time dummy $(\mathrm{t})$ & $-.4211(.3218)$ & $.3739(.3458)$ \\
\hline & $\mathrm{e} \cdot \mathrm{d} \cdot \mathrm{t}$ & $-.3526(.4426)$ & $-.5904(.4693)$ \\
\hline & $e \cdot t+e \cdot d \cdot t$ & $-.7737^{* *}(.3039)$ & $-.2166(.3172)$ \\
\hline
\end{tabular}

Robust standard errors in parenthesis. Significance at: $1 \% ; 5 \% ; 10 \%$.

\section{Closing remarks}

In this work, we developed a firm-level empirical analysis to evaluate the impact on firm performances of a sequence of earthquakes occurred in 2012 in the Italian region of Emilia-Romagna. This study addresses the question of whether the localization of a firm within an industrial district mitigated or exacerbated the impact of a local natural disaster.

Our findings suggest that the earthquake reduced turnover, production, value added, and return on sales of the surviving firms, at least in the short-term. In addition, the debt over sales ratio grew significantly more in the firms located in the areas affected by the earthquake.

The empirical evidence also suggests that the negative impact of the earthquake was slightly higher for the firms located in industrial districts than for those outside such areas, thereby suggesting that, at least in the short-term, the usually positive cumulative processes associated with localization within an agglomerated area could have reversed and magnified the negative impact of a disruptive exogenous supply shock. In this sense, counting on the "miraculous" properties of the industrial district to absorb the devastating effects of a natural disaster risks may be a mistake. This is probably the main contribution of this chapter to the industrial district debate.

Some policy implications can be drawn from our analysis. First, since the economic impact of a local disaster can be "small" (as in our case), public institutions should avoid misallocating public resources to finance interventions for areas hit by a natural disaster, without a serious and rigorous analysis of the real impact of the event. Second, these public policies should discriminate their interventions taking into account also of the localization within a region of industrial districts. Our evidence shows that, 
within these local productive systems, the effects of a local disaster can be amplified. Finally, these public interventions should also account for indirect effects. These effects can be propagated through vertical relationships/supply chain networks typical of clusters/industrial districts and more generally of agglomerated areas.

Three final caveats are in order. First, our analysis refers to surviving firms. This approach understates the overall impact of the earthquake, as it neglects its impact on firms' survival probabilities, and fails to capture the effects of participating in an industrial district to the likelihood of surviving to the shock. Second, we do not account for differences in the intensity of the earthquake in different geographical areas and model instead the earthquake as a binary treatment. This can bias some of the results in case of a systematic relation between the severity of the earthquake and some of the characteristics under study (and the bias can actually go both ways and cannot be easily inferred). Third, we do not control for the extent and timeliness of public intervention in the different areas. In fact, one could even argue that it is the readiness and appropriateness of such intervention the main reason behind the mild impact of the earthquake on firms' profitability we found.

Our future research will be therefore devoted to overcome these limitations. In particular, we plan to: (i) estimate the impact of the earthquake on firms' survival to come to an estimate of its overall effect on firms' profitability; (ii) account for possible systematic relations between firms' characteristics (e.g., the fact that they belong to an industrial district) and the severity of the earthquake, so as to check the robustness of our results, by using data on the intensity of the quakes across the different municipalities; (iii) control for the extent and timeliness of public intervention in the different locations, so as to come to an estimate of its effectiveness and obtain also an estimate of the impact of the earthquake net of public support. We believe that these developments can offer new insights not only for the debate on the economic impact of natural disasters, but also for the discussion on the mechanisms underlying the functioning of an industrial district.

\section{References}

Ahlerup, P. (2013). Are Natural Disasters Good for Economic Growth? Working Papers in Economics 553, University of Gothenburg, Department of Economics.

Barone, G. and S. Mocetti (2014). Natural Disasters, Growth and Institutions: A tale of Two Earthquakes. Journal of Urban Economics 84, 52-66.

Becattini G. (1989), Sectors and/or Districts: Some Remarks on the Foundations of Industrial Economies, Small Firms and Industrial Districts (eds. E. Goodman and J. Bamford), Routledge, London. 
Belasen, A. and C. Dai (2014). When Oceans Attack: Assessing the Impact of Hurricanes on Localized Taxable Sales. The Annals of Regional Science 52(2), 325-342.

Bianchi G. (1994), Tre e più Italie: Sistemi Territoriali di Piccola Impresa e Transizione PostIndustriale, Il Mosaico e il Progetto: Lavoro, Imprese, Regolazione nei Distretti Industriali della Toscana (ed. F. Bortolotti), Franco Angeli, Milan.

Brioschi F., Brioschi M.S. and Cainelli G. (2002), From the Industrial District to the District Group. An Insight into the Evolution of Local Capitalism in Italy, Regional Studies 36(9), 1037-1052.

Brusco S. (1982), The Emilian Model: Productive Decentralisation and Social Integration, Cambridge Journal of Economics 6(2), 167-184.

Brusco S., Cainelli G., Forni F., Franchi M., Malusardi A. and Righetti R. (1996), The Evolution of Industrial Districts in Emilia Romagna, Local Response to Global Pressures: the Case of Italy and its Industrial Districts (eds. F. Cossentino, F. Pyke and W. Sengenberger), Research Series n. 103, International Labour Office (ILO), Geneva.

Dei Ottati G. (1994), Trust, Interlinking Transactions and Credit in the Industrial District, Cambridge Journal of Economics 18(6), 529-546.

Cainelli G. and Zoboli R. (2004), The Evolution of Industrial Districts. Changing Governance, Innovation and Internationalization of Local Capitalism in Italy, Contributions to Economics, Physica Verlag, Heidelberg.

Cainelli G. (2008a), Agglomeration, Technological Innovations and Firm Productivity. Evidence from Italian Industrial Districts. Growth and Change 39(3), 414-435.

Cainelli G. (2008b), Industrial Districts. Theoretical and Empirical Insights, Handbook of Research on Cluster Theory (ed. C. Karlsson), Edward Elgar Publishing, Cheltenham, 189-202.

Cainelli, G., S. Montresor, and G. Vittucci Marzetti (2012). Production and financial linkages in interfirm networks: structural variety, risk-sharing and resilience. Journal of Evolutionary Economics 22(4), 711-734.

Carvalho, V. M., N. Makoto, and S. Yukiko (2014). Supply Chain Disruptions: Evidence from the Great East Japan Earthquake. Discussion papers 14035, Research Institute of Economy, Trade and Industry (RIETI).

Cavallo, E., S. Galiani, I. Noy, and J. Pantano (2013). Catastrophic Natural Disasters and Economic Growth. The Review of Economics and Statistics 95(5), 1549-1561.

Cavallo, E. and I. Noy (2009). The Economics of Natural Disasters: A Survey. Research Department Publications 4649, Inter-American Development Bank, Research Department.

Coelli, F. and P. Manasse (2014). The impact of floods on firms' performance. Working Paper DSE 946, Department of Economics, University of Bologna. 
Cole, M. A., R. J. R. Elliott, T. Okubo, and E. Strobl (2013). Natural Disasters and Plant Survival: The impact of the Kobe earthquake. Discussion Papers 13063, Research Institute of Economy, Trade and Industry (RIETI).

Cole, M. A., R. J. R. Elliott, T. Okubo, and E. Strobl (2015). Natural Disasters, Industrial Clusters and Manufacturing Plant Survival. Discussion Papers 15008, Research Institute of Economy, Trade and Industry (RIETI).

Cunado, J. and S. Ferreira (2014). The Macroeconomic Impacts of Natural Disasters: The Case of Floods. Land Economics 90(1), 149-168.

Fabling, R., A. Grimes, and L. Timar (2014). Natural Selection: Firm Performance Following the Canterbury Earthquakes. Working Papers 14 08, Motu Economic and Public Policy Research.

Fomby, T., Y. Ikeda, and N. V. Loayza (2013). The Growth aftermath of Natural Disasters. Journal of Applied Econometrics 28(3), 412-434.

Hallegatte, S. and P. Dumas (2009). Can natural disasters have positive consequences? Investigating the role of embodied technical change. Ecological Economics 68(3), 777-786.

Hayakawa, K., T. Matsuura, and F. Okubo (2015). Firm-level impacts of natural disasters on production networks: Evidence from a flood in Thailand. Journal of the Japanese and International Economies 38, 244-259.

Henriet, F., S. Hallegatte, and L. Tabourier (2012). Firm-network characteristics and economic robustness to natural disasters. Journal of Economic Dynamics and Control 36(1), 150-167.

Hosono, K., D. Miyakawa, T. Uchino, M. Hazama, A. Ono, H. Uchida and I. Uesugi (2016). Natural Disasters, Damage to Banks, and Firm Investment, International Economic Review 57, 1335-1370.

Imaizumi, A., K. Ito and T. Okazaki (2016). Impact of Natural Disasters on Industrial Agglomeration: The case of the Great Kantō Earthquake in 1923, Explorations in Economic History 60(C), 52-68.

Kousky, C. (2014). Informing Climate Adaptation: A Review of the Economic Costs of Natural Disasters. Energy Economics 46, 576-592.

Lazzaroni, S. and P. A. van Bergeijk (2014). Natural Disasters' Impact, Factors of Resilience and Development: A Meta-analysis of the Macroeconomic Literature. Ecological Economics 107, 333-346.

Leiter, A., H. Oberhofer, and P. Raschky (2009). Creative Disasters? Flooding Effects on Capital, Labour and Productivity Within European Firms. Environmental \& Resource Economics 43(3), 333350.

Loayza, N. V., E. Olaberría, J. Rigolini, and L. Christiaensen (2012). Natural Disasters and Growth: Going Beyond the Averages. World Development 40(7), 1317-1336.

Marshall A. (1920), Principles of Economics, Macmillan, London.

Mel, S. D., D. McKenzie, and C. Woodruff (2012). Enterprise Recovery Following Natural Disasters. 
Economic Journal 122(559), 64-91.

Merz, M., M. Hiete, T. Comes, and F. Schultmann (2013). A composite indicator model to assess natural disaster risks in industry on a spatial level. Journal of Risk Research 16(9), 1077-1099.

Noy, I. (2009, March). The Macroeconomic Consequences of Disasters. Journal of Development Economics 88(2), 221-231.

Raddatz, C. (2007). Are External Shocks Responsible for the Instability of Output in Low-Income Countries? Journal of Development Economics 84(1), 155-187.

Skidmore, M. and H. Toya (2002). Do Natural Disasters Promote Long-Run Growth? Economic Inquiry 40(4), 664-687.

Strobl, E. (2011). The Economic Growth Impact of Hurricanes: Evidence from U.S. Coastal Counties. The Review of Economics and Statistics 93(2), 575-589.

Todo, Y., K. Nakajima, and P. Matous (2013). How Do Supply Chain Networks Affect the Resilience of Firms to Natural Disasters? Evidence from the Great East Japan Earthquake. Discussion Papers 13028, Research Institute of Economy, Trade and Industry (RIETI).

Tokui, J., K. Kawasaki and T. Miyagawa (2017) The Economic Impact of Supply Chain Disruptions from the Great East-Japan Earthquake, Japan and the World Economy 41, 59-70.

Uchida, H., D. Miyakawa, K. Hosono, A. Ono, T. Uchino, and I. Uesugi (2013). Natural Disaster and Natural Selection. Working Paper 25, Center for Interfirm Network, Institute of Economic Research, Hitotsubashi University.

Vu, T. B. and I. Noy (2016). Natural Disasters and Firms in Vietnam. Pacific Economic Review, forthcoming. 